\title{
CÁC NHÂN TỐ ẢNH HƯởNG ĐẾN GIÁ MUA CĂN Hộ THƯƠNG MẠI TẠI CÁC KHU DÂN CƯ TRÊN ĐỊA BÀN THÀNH PHỐ CẦN THƠ
}

\author{
- Phạm Thị Thu Trang ${ }^{(*)}$, Tô Minh Chiến("*), \\ Tăng Thị Ngân ${ }^{(* *)}$, Nguyễn Minh Tân ${ }^{(* *)}$
}

\section{Tóm tắt}

Nghiên cứu được thực hiện nhằm xác định các nhân tố ảnh hưởng đến giá mua căn hộ tại các khu dân cu trên địa bàn thành phố Cần Tho: Mô hình Hedonic được sử dụng để xác định các nhân tố ảnh huơơng đến giá mua căn hộ, dựa trên kết quả khảo sát tù 183 hộ dân tại 10 khu dân cu ở quận Ninh Kiều và quận Cái Răng. Kết quả phân tích có 10 nhân tố tác động đến giá mua căn hộ bao gồm: tuổi căn hộ, diện tích căn hộ, số phòng, số tầng, vị trí tọa lạc, khoảng cách đến đường chính, khoảng cách đến trung tâm thành phố, kỳ vọng về giá, sổ hồng và loại căn hộ. Dựa trên kết quả phân tích, nhóm tác giả đề xuất những khuyến nghị nhằm phát triển và quản lý thị truờng nhà ở tại các khu dân cu trên địa bàn thành phố Cần Tho:

Tù khóa: Mô hình Hedonic, nhân tố ảnh hưởng, giá mua căn hộ, khu dân cu, thành phố Cần Tho:

\section{1. Đặt vấn đề}

Cần Thơ là trung tâm kinh tế lớn nhất ở khu vực Đồng bằng sông Cửu Long (ĐBSCL), với diện tích tự nhiên $1.409 \mathrm{~km}^{2}$, dân số khoảng 1,2 triệu người, thu nhập bình quân trên đầu người tính trong sáu tháng đầu năm 2012 đạt 51,172 triệu đồng/người [4]. Theo thống kê thành phố Cần Thơ (TPCT) có khoảng $20 \%$ cán bộ công nhân viên chức và 50.000 hộ nghèo chưa có nhà ở [9]. Nhu cầu về nhà ở tại đây đang có xu hướng tăng rất cao. Cần Thơ đã có những giải pháp nhằm hỗ trợ công tác phát triển các dự án nhà ở xã hội, nhà ở dành cho người thu nhập thấp trên toàn tỉnh. Cùng với định hướng phát triển kiến trúc và hệ thống hạ tầng kỹ thuật hoàn chỉnh của TPCT, hiện nay thị trường nhà ở đang phát triển và thu hút sự quan tâm của các nhà đầu tư. Theo Sở Xây dựng TPCT, trên địa bàn TPCT hiện có 88 dự án bất động sản, trong đó $69 / 88$ dự án xây dựng nhà ở xã hội và nhà ở thương mại còn hiệu lực với tổng diện tích 1.920,71 ha, trong đó diện tích quy hoạch nhà ở là $141.657 \mathrm{~m}^{2}$, tương ứng với 1.561 lô nền. Tuy nhiên, trong điều kiện kinh kế còn khó khăn, khi thị trường bất động sản đang đi vào trình trạng đóng băng, nhiều dự án khu dân cư (KDC) chưa tìm được đầu ra, thì vấn đề nghiên cứu để nhà đầu tư đưa ra mức giá thích hợp, nhằm đáp ứng được nhu cầu nhà ở thật sự của người dân là cần thiết.

\footnotetext{
(*) Trường Đại học Cần Thơ.

${ }^{(*)}$ Trường Cao đẳng Kinh tế - Kỹ thuật Cần Thơ.

${ }^{(* * *)}$ Trường Đại học Kỹ thuật - Công nghệ Cần Thơ.
}

Do đó, bài viết "Các nhân tố ảnh hưởng đến giá mua căn hộ thương mại tại các khu dân cư trên địa bàn TPCT" được nhóm tác giả thực hiện nhằm góp phần giải quyết các vấn đề nêu trên.

\section{Lược khảo tài liệu}

Ridker và Henning (1967) [7] đã khám phá 03 nhóm nhân tố ảnh hưởng đến giá nhà trong khu vực nghiên cứu, bao gồm đặc điểm kết cấu nhà ở, đặc điểm $\mathrm{KDC}$ và môi trường đặc trưng tại khu vực nhà ở. Trong đó, tác giả nhấn mạnh sự ô nhiễm không khí làm giảm giá trị của nhà ở, phương pháp định giá Hedonic được ứng dụng để ước tính giá trị các vấn đề môi trường và những đặc điểm liên quan đến nhà ở tác động đến giá trị của nhà ở. Bên cạnh đó, Chung-Ho và Kyung-Hwan (1999) [2] chứng minh rằng, khi người ta kỳ vọng giá tăng, giá tăng ngay sau khi có thông báo nới lỏng sự kiểm soát. Tuy nhiên, trong dài hạn mức giá giảm xuống rất nhanh và thấp hơn mức giá khi còn được kiểm soát. Ngoài ra, kỳ vọng về giá cũng tác động đến giá giao dịch của thị trường nhà ở. Nếu các nhà đầu tư có thể thay đổi cơ cấu kỳ vọng, họ có thể tránh những biến đổi đột ngột của thị trường. Thêm vào đó, Tse và Love (2000) [10] cho thấy diện tích nhà và sự có sẵn của bãi đỗ xe ảnh hưởng mạnh đến giá nhà ở, khi diện tích tăng, giá nhà cũng tăng theo. Ngược lại, nhà được xây dựng càng lâu có giá giao dịch càng thấp. Khoảng cách từ nhà đến trung tâm thể thao cũng như đến nghĩa trang càng gần làm cho giá nhà càng giảm. Ngoài ra, Hai-zhen (2005) [12], cho thấy có khá nhiều nhân tố ảnh hưởng đến giá nhà: diện tích sàn, 
khoảng cách đến trung tâm thương mại, điều kiện giao thông, bãi đậu xe, mức độ trang trí, quản lý khu vực, gác mái, số tầng nhà, thời gian giao dịch, khu vực giải trí, gần trường đại học.

Tại Việt Nam, Trần Thu Vân và Nguyễn Thị Giang (2011) [11] cho thấy, các nhân tố tác động đến giá bất động sản (BĐS) bao gồm: diện tích đất, diện tích nhà, khoảng cách $\mathrm{BĐS}$ đến trung tâm thành phố và khoảng cách từ $B Đ S$ đến mặt tiền đường; trong đó, vị trí tọa lạc của $\mathrm{B} Đ S$ có ảnh hưởng mạnh nhất. Giá $\mathrm{BĐS}$ tọa lạc trong hẻm thấp hơn giá $\mathrm{BĐS}$ tọa lạc trên mặt tiền đường; trung bình $\mathrm{BĐS}$ nằm sâu trong hẻm thêm $1 \mathrm{~m}$, giá trị giao dịch giảm $0,14 \%$. Ngược lại, khoảng cách từ vị trí tọa lạc đến trung tâm thành phố tỷ lệ nghịch với giá của $\mathrm{BĐS}$ vì $\mathrm{BĐS}$ ở vị trí càng xa trung tâm, giá trị được giao dịch càng giảm. Hai yếu tố diện tích nhà và diện tích đất tỷ lệ thuận với giá của $\mathrm{BĐS}$ mặc dù hệ số ảnh hưởng là không lớn. Trong khi đó, Lê Khương Ninh (2011) [5] cho thấy đối với đất thổ cư thì khoảng cách càng xa trung tâm thương mại, trường học và đường chính, giá đất càng thấp. Thêm vào đó, thửa đất ở mặt tiền đường rộng từ 3,5 mét trở lên có giá cao hơn các thửa đất khác, mức độ ô nhiễm nguồn nước tăng, giá đất sẽ giảm. Ngoài ra, khu vực có mức độ an ninh cao, giá đất cũng cao hơn những nơi khác. Quy hoạch treo làm giảm giá đất vì người sử dụng không thể khai thác đất để sinh lợi; loại hình đô thị càng cao, giá đất sẽ càng cao. Đáng lưu ý nhất là nếu kỳ vọng giá đất tăng lên, người giao dịch trên thị trường đất đai chấp nhận mức giá cao hơn. Kỳ vọng về sự tăng lên của giá đất xuất phát từ thông tin các dự án đầu từ phát triển hệ thống kết cấu hạ tầng, sự ra đời của các trung tâm thương mại, khu hành chính, KDC, khu công nghiệp. Nguyễn Quốc Nghi và cộng tác viên (2012) [3] cho rằng, với thị trường nhà ở, các nhân tố diện tích, số phòng tắm, hướng nhà, vị trí, trục đường chính, kỳ vọng và thu nhập có tác động làm tăng giá nhà ở. Bên cạnh đó, các biến số tầng nhà, khoảng cách trung tâm, môi trường lại có tác động nghịch chiều với giá nhà ở tại TPCT.

Tóm lại, các nghiên cứu trên đã tìm ra được các yếu tố ảnh hưởng đến giá BĐS như: nhà ở, đất thổ cư, đất quy hoạch... theo từng điều kiện vị trí địa lý cụ thể. Kết quả các nghiên cứu trên sẽ làm cơ sở nghiên cứu cho trường hợp phân tích các nhân tố ảnh hưởng đến giá mua căn hộ thương mại tại các KDC trên địa bàn TPCT. Trong đó, tác giả sử dụng phương pháp định giá Hedonic để phân tích, đồng thời tác giả chọn lọc các yếu tố phù hợp với đặc điểm nghiên cứu tại các khu nhà ở thương mại ở TPCT làm các yếu tố độc lập trong mô hình nghiên cứu.

\section{Phương pháp nghiên cứu}

\subsection{Khung lý thuyết}

Phương pháp định giá Hedonic được định nghĩa là kỹ thuật phân tích hồi quy được dùng để xác định giá trị của những thuộc tính liên quan đến hàng hóa trên thị trường trong các giai đoạn cụ thể. Mô hình hồi quy Hedonic được xây dựng dựa trên lý thuyết hàng hóa là một tập hợp của nhiều đặc tính khác nhau, và giá của hàng hóa cũng được gắn liền với các đặc tính này. Nhưng một số đặc tính không lượng hóa được nên được thể hiện dưới dạng biến giả. Hệ số của các biến trong mô hình hồi quy thể hiện mức độ đóng góp, tác động của đặc tính đó đến giá chung của hàng hóa. Sự ước tính này có thể được dùng để đánh giá những đặc điểm tương tự dù hàng hóa có thể mới hoặc khác so với hàng hóa chứa thuộc tính đó (Hệ thống tài khoản quốc gia của Hòa Kỳ, 1993, Đoạn 16.126).

Theo Griliches (1971) [1], phương pháp Hedonic dựa trên cơ sở: giá của một hàng hóa không đồng nhất có thể được xác định thông qua những thuộc tính liên quan đến hàng hóa đó. Vì thế, hàm hồi quy Hedonic có dạng:

$$
\mathrm{pi}=\mathrm{h}(\mathrm{ci})
$$

Với pi là giá của hàng hóa và ci là vector của các đặc tính liên quan đến hàng hóa.

Theo Malpezzi (1980) [8], trong quá trình phát triển, thị trường nhà ở là một trong những ứng dụng rộng rãi của mô hình định giá Hedonic, vì nhà ở là hàng hóa không đồng nhất, đồng thời nhu cầu của người tiêu thụ cũng không đồng nhất. Thật vậy, một căn hộ gồm nhiều đặc điểm riêng biệt về diện tích, chất lượng, vị trí... Mỗi căn nhà có một vị trí nhất định, thời gian xây dựng khác nhau, có diện tích khác nhau. Bên cạnh đó, mức độ thỏa dụng của người mua khác nhau, định giá căn hộ cũng khác nhau. Một căn hộ có cùng một nhóm đặc điểm được định giá khác nhau theo từng người mua. Việc định giá vì thế cũng trở nên khó khăn. Do đó, phương pháp Hedonic được sử dụng phổ 
biến vì nó ước tính được giá trị của các đặc điểm riêng lẻ cấu thành nên giá trị chung của căn hộ.

Theo nghiên cứu tổng hợp về ứng dụng mô hình Hedonic trong thị trường nhà ở của Ozanne, Thibodeau và Malpezzi được thực hiện năm 1980 [8], phương pháp định giá Hedonic là một mô hình hồi quy của giá trị hoặc giá thuê căn hộ dựa trên những đặc tính liên quan đến căn hộ. Trong đó, từng biến độc lập đại diện cho từng đặc điểm riêng biệt và các hệ số trong kết quả của mô hình là giá tiềm ẩn của những đặc điểm này, mô hình hồi quy của giá cho thuê hoặc giá trị căn hộ có dạng:

$$
\mathrm{R}=\mathrm{f}(\mathrm{S}, \mathrm{N}, \mathrm{L}, \mathrm{C}, \mathrm{T})
$$

Trong đó: $\mathrm{R}$ là giá thuê hoặc giá trị căn hộ; $\mathrm{S}$ là những đặc điểm thuộc cấu trúc; $\mathrm{N}$ là đặc điểm thuộc môi trường xung quanh; $\mathrm{L}$ là vị trí; $\mathrm{C}$ là đặc điểm về hợp đồng giao dịch và $\mathrm{T}$ là thời hạn căn hộ được quan sát.

\subsection{Mô hình ước lượng}

Thị trường nhà ở đã phát triển và được nghiên cứu từ nhiều năm qua với nhiều khía cạnh khác nhau tại các nước trên thế giới. Tuy nhiên, tại Việt
Nam, đặc biệt là ĐBSCL, những nghiên cứu về thị trường nhà ở, đặc biệt nhà ở tại các $\mathrm{KDC}$ vẫn còn khá mới mẻ. Thông qua việc tham khảo các mô hình nghiên cứu trước đây kết hợp với phỏng vấn trực tiếp từ thực tế, tác giả đề xuất mô hình định giá nhà ở như sau:

$$
\operatorname{Ln}(\mathrm{P})=\beta 0+\beta 1 \mathrm{TUOI}+\beta 2 \text { DIENTICH }+
$$
$\beta 3 \mathrm{SOPHONG}+\beta 4 \mathrm{HUONG}+\beta 5 \mathrm{SOTANG}+$ $\beta 6$ VITRI $+\beta 7 \mathrm{KCDC}+\beta 8 \mathrm{KCTT}+\beta 9 \mathrm{KCTH}+$ $\beta 10 \mathrm{KCLV}+\beta 11 \mathrm{DUONGNB}+\beta 12 \mathrm{VIAHE}+$ $\beta 13$ ANNINH $+\beta 14$ KYVONG $+\beta 15$ LOAICH + $\beta 16 \mathrm{SOHONG}$

Trong mô hình trên, biến phụ thuộc $\left(\mathrm{P} / \mathrm{m}^{2}\right)$ là giá căn hộ giao dịch trên thị trường (triệu đồng $/ \mathrm{m}^{2}$ ). Theo nghiên cứu của các tác giả đã thực nghiệm trước, các nhân tố ảnh hưởng giá nhà được phân chia thành từng nhóm đặc điểm để nghiên cứu. Ứng dụng vào mô hình nghiên cứu này, tác giả phân thành 4 nhóm gồm nhóm đặc điểm thuộc về cấu trúc, nhóm đặc điểm thuộc vị trí, nhóm đặc điểm thuộc $\mathrm{KDC}$ và nhóm đặc điểm khác. Sau đây là bảng diễn giải các biến đo lường.

\begin{tabular}{|c|c|c|c|c|}
\hline Tên biến & Diễn giải biến & Đơn vị tính & Căn cứ chọn biến & $\begin{array}{c}\text { Kỳ } \\
\text { vọng }\end{array}$ \\
\hline TUOI & $\begin{array}{l}\text { Tuổi căn hộ hay số năm hoạt } \\
\text { động tính đến thời điểm khảo sát }\end{array}$ & năm & $\begin{array}{l}\text { Ronald G. Ridker, John A. } \\
\text { Henning, } 1967\end{array}$ & - \\
\hline DIENTICH & Tổng diện tích sàn nhà & $\mathrm{m}^{2}$ & $\begin{array}{l}\text { Chung-Ho Kim, Kyung-Hwan } \\
\text { Kim, 1999; Ronald G. Ridker, } \\
\text { John A. Henning, 1967; Lê } \\
\text { Khương Ninh, 2011 } \\
\end{array}$ & + \\
\hline SOTANG & $\begin{array}{l}\text { Số tầng của căn hộ (không vượt } \\
\text { hơn } 06 \text { tầng) }\end{array}$ & tầng & Wen Hai-zhen, 2005 & - \\
\hline SOPHONG & $\begin{array}{l}\text { Số lượng các phòng chức năng } \\
\text { của căn hộ }\end{array}$ & phòng & $\begin{array}{l}\text { Chung-Ho Kim, Kyung-Hwan } \\
\text { Kim, } 1999 \\
\end{array}$ & + \\
\hline HUONG & Hướng mặt tiền của căn hộ & $\begin{array}{l}=1 \text { nếu hướng nhà là Đông } \\
\text { hoặc Đông Nam; } \\
=0 \text { là hướng khác }\end{array}$ & $\begin{array}{l}\text { Quyết định } \\
\text { 207/2006/QĐ-TTg, } 2006\end{array}$ & + \\
\hline VITRI & Vị trí tọa lạc của căn hộ & $\begin{array}{l}=1 \text { nếu căn hộ ở ngay góc } \\
\text { ngã ba, ngã tư của KDC; } \\
=0 \text { nếu vị trí khác }\end{array}$ & Lê Khương Ninh, 2011 & + \\
\hline $\mathrm{KCDC}$ & $\begin{array}{l}\text { Khoảng cách từ căn hộ đến trục } \\
\text { đường chính }\end{array}$ & $\mathrm{m}$ & Lê Khương Ninh, 2011 & - \\
\hline KCTT & $\begin{array}{l}\text { Khoảng cách từ căn hộ đến trung } \\
\text { tâm thành phố }\end{array}$ & $\mathrm{km}$ & $\begin{array}{l}\text { Chung-Ho Kim, Kyung-Hwan } \\
\text { Kim, 1999; Lê Khương Ninh, } \\
\text { 2011; Trần Thu Vân và Nguyễn } \\
\text { Thị Giang, } 2011\end{array}$ & - \\
\hline
\end{tabular}

Bảng 1. Diễn giải các biến trong mô hình nghiên cứu 


\begin{tabular}{|l|l|c|l|c|}
\hline KCTH & Khoảng cách đến trường học & $\mathrm{km}$ & $\begin{array}{l}\text { Chung-Ho Kim, Kyung-Hwan } \\
\text { Kim, 1999; Lê Khương Ninh, } \\
\text { 2011; Trần Thu Vân và Nguyễn } \\
\text { Thị Giang, 2011 }\end{array}$ & - \\
\hline DUONGNB & $\begin{array}{l}\text { Giới hạn đường nội phía trước } \\
\text { căn hộ }\end{array}$ & $\mathrm{km}$ & $\begin{array}{l}\text { Chung-Ho Kim, Kyung-Hwan } \\
\text { Kim, 1999; Wen Hai-zhen, 2005 }\end{array}$ & + \\
\hline VIAHE & Giới hạn vỉa hè phía trước căn hộ & $\mathrm{m}$ & $\begin{array}{l}\text { Chung-Ho Kim, Kyung-Hwan } \\
\text { Kim, 1999; Wen Hai-zhen, 2005 }\end{array}$ & + \\
\hline KYVONG & Biến kỳ vọng về giá khi mua nhà & $\%$ & $\begin{array}{l}\text { Raymond Y.C. Tse, Peter E.D. } \\
\text { Love, 2000; Trần Thu Vân và } \\
\text { Nguyễn Thị Giang, 2011 }\end{array}$ & + \\
\hline SOHONG & $\begin{array}{l}\text { Giấy chứng nhận quyền sử dụng } \\
\text { đất và sở hữu nhà ở }\end{array}$ & $\begin{array}{l}=1 \text { nếu được cấp sổ hồng; } \\
=0 \text { nếu ngược lại }\end{array}$ & $\begin{array}{l}\text { Chung-Ho Kim, Kyung-Hwan } \\
\text { Kim, 1999 }\end{array}$ & + \\
\hline LOAICH & $\begin{array}{l}\text { Loại căn hộ khi mua đã được xây } \\
\text { hoàn thiện hay xây thô }\end{array}$ & $\begin{array}{l}\text { 1 nếu là căn hộ xây thô; } \\
=0 \text { nếu được xây hoàn } \\
\text { thiện }\end{array}$ & $\begin{array}{l}\text { Chung-Ho Kim, Kyung-Hwan } \\
\text { Kim, 1999 }\end{array}$ & - \\
\hline
\end{tabular}

\subsection{Phương pháp thu thập số liệu}

Nguồn: Tác giả tổng hợp tù các nghiên cứu có liên quan

Nghiên cứu áp dụng phương pháp chọn mẫu phân tầng kết hợp với ngẫu nhiên. Tiêu chí phân tầng là quận, ở mỗi quận sẽ chọn ra một số KDC, chọn độc lập trong mô hình. Nghiên cứu sử dụng 16 biến ngẫu nhiên căn hộ thuộc KDC để phỏng vấn. Đối độc lập, do đó cỡ mẫu được chọn phải lớn hơn 178 tượng được phỏng vấn là người mua, người đang quan sát, nhóm tác giả tiến hành phỏng vấn 183 hộ sở hữu căn hộ tại các KDC. Kích thước mẫu được để thực hiện trong nghiên cứu. tính theo công thức $\mathrm{n} \geq 50+8 \mathrm{p}$. Trong đó, $\mathrm{n}$ là kích thước mẫu tối thiểu cần thiết, $\mathrm{p}$ là số lượng biến

\section{Kết quả nghiên cứu}

4.1. Mô tả mẫu khảo sát

Bảng 2. Đặc điểm các yếu tố trong mô hình nghiên cứu

\begin{tabular}{llccccc}
\hline \multicolumn{1}{c}{ Chỉ tiêu } & \multicolumn{1}{c}{ Biến } & ĐVT & $\begin{array}{c}\text { Giá trị } \\
\text { trung bình }\end{array}$ & $\begin{array}{c}\text { Độ lệch } \\
\text { chuẩn }\end{array}$ & $\begin{array}{c}\text { Giá trị } \\
\text { thấp nhất }\end{array}$ & $\begin{array}{c}\text { Giá trị } \\
\text { cao nhất }\end{array}$ \\
\hline $\mathrm{P}$ & Giá mua căn hộ & triệu đồng & $1.073,67$ & 548,89 & 520 & 3.500 \\
TUOI & Tuổi căn hộ & năm & 5,17 & 1,87 & 1 & 9 \\
DIENTICH & Tổng diện tích căn hộ & $\mathrm{m}^{2}$ & 210,06 & 89,97 & 80 & 600 \\
SOTANG & Số tầng & tầng & 2,88 & 0,62 & 2 & 4 \\
SOPHONG & Số phòng & phòng & 5,81 & 1,21 & 4 & 10 \\
HUONG & Hướng căn hộ & $1 / 0$ & 0,22 & 0,41 & 0 & 1 \\
VITRI & Vị trí tọa lạc & $1 / 0$ & 0,14 & 0,34 & 0 & 1 \\
KCDC & Khoảng cách đến đường chính & $\mathrm{m}$ & 124,07 & 129,01 & 0 & 1.000 \\
KCTT & Khoảng cách đến trung tâm thành phốn & $\mathrm{km}$ & 5,07 & 1,40 & 1,5 & 7,5 \\
KCTH & Khoảng cách đến trường học & $\mathrm{km}$ & 3,33 & 3,62 & 0,1 & 40 \\
DUONGNB & Giới hạn đường nội bộ & $\mathrm{m}$ & 7,14 & 2,11 & 4 & 14 \\
VIAHE & Giới hạn vỉa hè & $\mathrm{m}$ & 3,43 & 0,83 & 2 & 7,5 \\
KYVONG & Kỳ vọng về giá căn hộ & $\%$ & 5,99 & 11,21 & -20 & 50 \\
SOHONG & Cấp sổ hồng & $1 / 0$ & 0,52 & 0,50 & 0 & 1 \\
LOAICH & Loại căn hộ & $1 / 0$ & 0,48 & 0,50 & 0 & 1 \\
\hline
\end{tabular}

Nguồn: Xư lý tù̀ số liệu điều tra tù 183 hộ, 2013 
Bảng 2 mô tả đặc điểm các biến trong mô hình nghiên cứu, dựa trên kết quả khảo sát từ 183 hộ gia đình.
4.2. Các nhân tố ảnh hưởng đến giá mua căn hộ thương mại tại các KDC trên địa bàn TPCT

Bảng 3. Kết quả phân tích hồi quy Hedonic

\begin{tabular}{lcccc}
\hline \multicolumn{1}{c}{ Chỉ tiêu } & Hệ số B & $\begin{array}{c}\text { Hệ số Beta } \\
\text { Chuẩn hóa }\end{array}$ & Mức ý nghĩa & VIF \\
\hline Hằng số & 5,035 & & $0,000^{* * *}$ & \\
Tuổi của căn hộ & $-0,263$ & $-0,317$ & $0,000^{* * *}$ & 1,228 \\
Diện tích căn hộ & $-0,331$ & $-0,240$ & $0,000^{* * *}$ & 1,718 \\
Số lượng phòng & $-0,220$ & $-0,111$ & $0,022^{* *}$ & 1,742 \\
Số tầng & $-0,276$ & $-0,153$ & $0,003^{* * *}$ & 1,989 \\
Hướng của căn hộ & $-0,016$ & $-0,016$ & 0,676 & 1,099 \\
Vị trí tọa lạc & $-0,122$ & $-0,105$ & $0,007^{* * *}$ & 1,099 \\
Khoảng cách đến đường chính & $-0,023$ & $-0,134$ & $0,002^{* * *}$ & 1,364 \\
Khoảng cách đến trung tâm thành phố & $-0,575$ & $-0,475$ & $0,000^{* * *}$ & 1,421 \\
Khoảng cách đến trường học & 0,008 & 0,018 & 0,648 & 1,113 \\
Giới hạn đường nội bộ & 0,028 & 0,023 & 0,587 & 1,396 \\
Giới hạn vỉa hè & 0,077 & 0,045 & 0,276 & 1,282 \\
Kỳ vọng giá căn hộ tăng & 0,002 & 0,069 & $0,070^{*}$ & 1,059 \\
Cấp sổ hồng & 0,114 & 0,141 & $0,001^{* * *}$ & 1,201 \\
Loại căn hộ & $-0,308$ & $-0,383$ & $0,000^{* * *}$ & 1,231 \\
\hline Mức ý nghĩa (Sig.F) & & & & 0,000 \\
Hệ số R ${ }^{2}$ hiệu chỉnh & & & 0,758 \\
Hệ số Durbin-Watson & & & 1,982 \\
\hline
\end{tabular}

Nguồn: Kết quả phân tích hồi quy số liệu điều tra của tác giả, 2013.

Ghi chú: *, **, *** thể hiện các biến có ý nghĩa lần luoot ơ múc $10 \%, 5 \%$ và $1 \%$.

Kết quả phân tích bảng 3 cho thấy: (1) Mức ý nghĩa quan sát Sig. của toàn mô hình rất nhỏ $($ Sig. $=0,000)$ cho thấy mô hình Hedonic được thiết lập phù hợp với cơ sở dữ liệu thu thập được. (2) Giá trị $\mathrm{R}^{2}$ điều chỉnh là 0,758 tức là có $75,8 \%$ sự thay đổi của giá căn hộ được giải thích bởi các biến độc lập có ý nghĩa trong mô hình. (3) Hệ số Durbin-Watson của mô hình là 1,982 , nằm trong khoảng quy định: $1,5<\mathrm{d}=2,034<2,5$ chứng tỏ mô hình không có hiện tượng tự tương quan. Bên cạnh đó, độ phóng đại phương sai (VIF) của các biến trong mô hình nhỏ hơn nhiều so với 10 nên ta kết luận các biến đưa vào mô hình không có hiện tượng đa cộng tuyến.

Trong số tất cả 14 yếu tố đưa vào mô hình nghiên cứu có 10 yếu tố có ý nghĩa thống kê ở mức $1 \%, 5 \%$ và $10 \%$. Trong đó, có 8 yếu tố mang dấu âm, nghĩa là có tương quan nghịch chiều với giá căn hộ và 2 yếu tố mang dấu dương tức có tương quan thuận chiều đến giá căn hộ. Các yếu tố Tuổi của căn hộ, Diện tích của căn hộ, Khoảng cách đến trung tâm, Loại căn hộ, Số tầng, Vị trí tọa lạc, Khoảng cách đến đường chính và Sổ hồng đều có ý nghĩa thống kê ở mức $1 \%$. Trong đó, các yếu tố Tuổi của căn hộ, Diện tích của căn hộ, Khoảng cách đến trung tâm, Loại căn hộ có tác động mạnh nhất đến giá căn hộ do có hệ số B lớn hơn các yếu tố còn lại (Bảng 3). Yếu tố Số lượng phòng có ý nghĩa ở mức $5 \%$. Yếu tố Kỳ vọng giá căn hộ tăng có ý nghĩa ở mức $10 \%$. Đây là 10 nhân tố có ảnh hưởng đến giá căn hộ tại các KDC trên địa bàn TPCT. Các nhân tố còn lại có mức ý nhĩa lớn hơn $\alpha=10 \%$ nên không có ý nghĩa thống kê.

Mô hình hồi quy được thiết lập như sau:

$\operatorname{Ln}(\mathrm{P})=5,035$ - 0,2631n (TUOI) - 0,331 ln (DIENTICH) - 0,2201n (SOPHONG) - 0,2761n 
(SOTANG) - 0,122 (VITRI) - 0,023ln (KCDC) $-0,575 \ln (\mathrm{KCTT})+0,002(\mathrm{KYVONG})+0,114$ (SOHONG) - 0,308 (LOAICH)

Hệ số căn hộ nhân tố TUOI (tuổi căn hộ) mang dấu âm (-), phù hợp với dấu kỳ vọng. Hệ số B mang giá trị $-0,263$ có nghĩa là khi căn hộ tăng thêm một tuổi sẽ làm giá mua căn hộ $/ \mathrm{m}^{2}$ giảm $26,3 \%$ khi các yếu tố khác không đổi. Thực tế cho thấy nhiều căn hộ được xây thô hoặc hoàn thiện tại các KDC thời gian xây dựng càng lâu càng làm cho giá trị của căn hộ bị giảm sút. Nhiều căn hộ tại KDC được xây dựng cách đây vài năm như Thiên lộc, KDC 586, KDC Nam Long người mua phải chi thêm một khoản tiền nữa để sửa lại nền gạch do bị lún, bị thấm nước ở một vài nơi mặc dù căn hộ đã được xây hoàn thiện. Do đó, người mua chấp nhận ở mức giá thấp hơn đối với căn hộ đã được xây dựng lâu hơn.

Hệ số của nhân tố DIENTICH (diện tích căn hộ) mang dấu âm (-) cho thấy khi diện tích tăng thêm $1 \mathrm{~m}^{2}$ thì giá căn hộ $/ \mathrm{m}^{2}$ sẽ giảm $33,1 \%$ khi các yếu tố khác không đổi. Dấu của hệ số ngược với dấu kỳ vọng. Thực tế cho thấy, do đặc điểm kết cấu nền đất mềm ở vùng Nam Bộ, nên khi xây dựng một căn hộ thì phần quan trọng và tốn nhiều chi phí nhất (thông thường khoảng $25 \%$ giá trị căn hộ) là phần móng. Do đó, chi phí xây dựng đối với các tầng lầu thường thấp hơn so với tầng trệt. Vì vậy, khi mua căn hộ có diện tích càng lớn thì giá trên căn hộ sẽ tăng, nhưng tính giá mua căn hộ $/ \mathrm{m}^{2}$ sẽ giảm hơn nhiều.

Hệ số của nhân tố SOPHONG (số phòng của căn hộ) mang dấu âm (-), ngược với dấu kỳ vọng. Hệ số $\mathrm{B}$ mang giá trị $-0,220$ tức là khi số phòng tăng lên 1 thì giá căn hộ/ $\mathrm{m}^{2}$ giảm $22 \%$ khi cố định các yếu tố khác. Về ưu điểm, số phòng càng nhiều càng thuận tiện cho các sinh hoạt của gia đình. Tuy nhiên, vì diện tích sàn xây dựng hiện nay ở các KDC tương đối gần giống nhau, nên khi nhà được bố trí nhiều phòng mà cụ thể là tăng thêm phòng ngủ thì phần diện tích cho các phòng sẽ bị thu hẹp lại. Cụ thể, tại KDC Thiên lộc đối với căn hộ xây hoàn thiện diện tích $128 \mathrm{~m}^{2}$, với số lượng 6 phòng trong đó tầng trệt được bố trí thêm 1 phòng ngủ. Cũng với diện tích này tại KDC Hưng Phú 2 căn hộ được bố trí với 5 phòng chủ yếu. Với xu hướng hiện nay, đa phần người dân chuộng cách bố trí phòng khách và phòng bếp được rộng rãi nên việc tăng thêm số lượng phòng ngủ sẽ giảm đi giá trị của căn hộ.
Hệ số của nhân tố SOTANG (số tầng của căn hộ) mang dấu âm (-), phù hợp với dấu kỳ vọng. Hệ số $\mathrm{B}$ mang giá trị $-0,276$ có nghĩa là khi số tầng tăng thêm 1 thì giá căn hộ $/ \mathrm{m}^{2}$ sẽ giảm $27,6 \%$ khi các yếu tố khác không đổi. Về ưu điểm, số tầng càng cao càng tiết kiệm được nhiều diện tích đất. Tuy nhiên, nhà có nhiều tầng sẽ gây bất tiện khi lên xuống cầu thang. Thêm vào đó, việc xây dựng nhà cao tầng đòi hỏi nền móng phải vững chắc và an toàn. Do đó, nếu cùng diện tích đất xây dựng thì nhà trệt hoặc thấp tầng sẽ được đánh giá cao hơn nhà cao tầng.

Theo kết quả phân tích, hệ số của nhân tố VITRI (vị trí căn hộ) mang dấu âm (-) điều này kết luận biến tỷ lệ nghịch với giá căn hộ. Kết quả cho thấy, với căn hộ ở ngay góc ngã ba, ngã tư của KDC giá $/ \mathrm{m}^{2}$ sẽ thấp hơn $12,2 \%$ giá căn hộ ở vị trí khác. Thực tế tại các KDC lớn như KDC 586, KDC Hưng Phú 2, KDC 91B mặc dù căn hộ ở ngay vị trí góc ngã ba, ngã tư của KDC nhưng do khoảng cách đến đường chính khá xa nên giá căn hộ này cũng không cao hơn những căn hộ có khoảng cách ở gần đường chính.

Hệ số của nhân tố KCDC (khoảng cách đến đường chính) mang dấu âm (-) và đúng với dấu kỳ vọng. Điều này giải thích căn hộ ở xa đường chính tăng thêm $1 \mathrm{~m}$ thì giá căn hộ $/ \mathrm{m}^{2}$ sẽ giảm $2,3 \%$ khi các yếu tố khác không đổi. Thật vậy, căn hộ ở trục đường chính hay càng gần đường chính ngoài sự thuận tiện về giao thông thì còn mang lại lợi ích về kinh tế vì có thể kinh doanh mua bán hoặc cho thuê mặt bằng. Do đó, căn hộ càng gần đường chính có giá càng cao.

Hệ số của nhân tố KCTT (khoảng cách đến trung tâm thành phố) mang dấu âm (-) và đúng với dấu kỳ vọng. Điều này giải thích khoảng cách từ căn hộ đến trung tâm thành phố tỷ lệ nghịch với giá căn hộ. Tác giả chọn trung tâm thành phố là quận Ninh Kiều và Đại lộ Hoà Bình là mốc để tính khoảng cách. Như vậy, nhà càng xa trung tâm thì giá càng thấp, hệ số $B$ là $-0,575$ cho thấy nếu khoảng cách đến trung tâm tăng thêm $1 \mathrm{~km}$ thì sẽ làm giảm $57,5 \%$ trên mỗi $m^{2}$ căn hộ khi các yếu tố khác không đổi. Qua khảo sát thực tế các KDC như Hưng Phú 1, 91B, Hồng Phát, KDC Vạn Phát cách trung tâm thành phố khoảng 1 đến $2 \mathrm{~km}$ đều có giá rất cao. Trong khi đó xa nhất là KDC Thiên Lộc hiện nay giá rất thấp do khoảng cách đến trung tâm thành phố khoảng $7 \mathrm{~km}$. 
Hệ số nhân tố KYVONG (kỳ vọng giá căn hộ tăng khi mua) manh dấu dương $(+)$ đúng với dấu kỳ vọng. Khi người mua kỳ vọng giá nhà tăng trong tương lai sẽ làm giá căn hộ tăng thêm $0,2 \%$ khi các yếu tố khác không đổi. Thực tế cho thấy, trong những năm vừa qua giá căn hộ đã được thổi lên rất cao do dự đoán về giá sẽ tăng trong tương lai. Khi giá căn hộ đã tăng lên đến đỉnh điểm hiện tượng đóng băng đã xảy ra vì người tiêu dùng không chú ý đến thị trường này nữa và chính điều này đã đem lại bất lợi cho giới đầu tư trong thị trường hôm nay khi giá căn hộ đã được điều chỉnh về giá trị thật của nó.

Hệ số nhân tố SOHONG (cấp sổ hồng) mang dấu dương $(+)$, đúng với dấu kỳ vọng. Hệ số $\mathrm{B}$ là 0,114 , điều này được giải thích là đối với căn hộ đã được cấp sổ hồng sẽ có giá cao hơn $11,4 \%$ so với căn hộ chưa được cấp sổ hồng. Trình trạng pháp lý của căn hộ hiện nay ở các KDC vẫn còn tồn tại, nhiều căn hộ đã được mua khá lâu nhưng theo nhiều hộ dân ở KDC cho biết việc hoàn thành thủ tục pháp lý vẫn chưa thực hiện được, mặc dù trên hợp đồng mua bán chủ đầu tư cam kết sẽ được cấp trong vòng 6 tháng sau khi mua căn hộ. Cũng theo nhận xét của Sở Tài nguyên và Môi trường, hiện nay do nhiều khu đất tại KDC đang trong giai đoạn thế chấp ngân hàng, nên không thể hoàn thành thủ tục cấp sổ hồng cho hộ dân cư. Chính yếu tố này làm cho giá căn hộ chưa có sổ hồng sẽ có mức giá thấp hơn.

Hệ số nhân tố LOAICH (loại căn hộ) mang dấu âm (-), đúng với dấu kỳ vọng. Hệ số $\mathrm{B}$ của nhân tố là $-0,308$, có nghĩa là căn hộ xây thô sẽ có mức giá $/ \mathrm{m}^{2}$ thấp hơn $30,8 \%$ so với căn hộ được xây hoàn thiện khi cố định các yếu tố khác. Với loại hình căn hộ xây thô được ưu chuộng hơn tại các KDC vì khách hàng có thể chủ động bố trí các phòng theo ý thích và dễ chọn vật liệu trang trí cho căn hộ. Qua khảo sát cho thấy để hoàn thiện căn hộ xây thô khách hàng thường chi thêm một khoản tiền bằng $30 \%$ - 40\% giá mua căn hộ và tuỳ vào thu nhập của chủ hộ mà căn hộ có thể được hoàn thiện với giá cao hơn.

Tuy nhiên, kết quả mô hình còn 4 nhân tố được chứng minh không có ý nghĩa thống kê là hướng căn hộ, khoảng cách đến trường học, giới hạn đường nội bộ và nhân tố giới hạn vỉa hè.

Theo mô hình, nhân tố hướng căn hộ mang kỳ vọng dương $(+)$, có nghĩa là khi căn hộ ở hướng
Đông hoặc Đông Nam sẽ có giá cao hơn căn hộ ở những hướng khác. Tuy nhiên, thực tế đối với chủ hộ có quan tâm đến hướng khi chọn mua nhà, thì không nhất thiết chọn hướng Đông hoặc hướng Đông Nam, mà khách hàng sẽ chọn căn hộ có hướng phù hợp với tuổi của chủ hộ. Vì thế, mặc dù trong kết quả nghiên cứu, biến này mang hệ số dương, chứng tỏ có quan hệ tương quan thuận chiều với biến phụ thuộc, nhưng sự khác nhau về hướng căn hộ không đủ mạnh để tác động đến giá căn hộ.

Tương tự, nhân tố khoảng cách đến trường học mang kỳ vọng âm (-), tức càng cách xa trường học thì giá căn hộ $/ \mathrm{m}^{2}$ sẽ giảm. Kết quả nghiên cứu biến mang hệ số dương chứng tỏ có tương quan nghịch chiều với biến phụ thuộc. Thực tế hiện nay một số KDC có trường học như KDC Thiên lộc, Nam Long, Hưng Phú 2 nhưng số lượng người học chưa nhiều. Chất lượng dạy và học là yếu tố được người dân quan tâm nhiều hơn, nên phần lớn con em được đi học ở các trường thuộc trung tâm thành phố. Do đó, biến khoảng cách đến trường học cũng không tác động đến giá căn hộ.

Nhân tố giới hạn đường nội bộ và giới hạn vỉa hè mang kỳ vọng dương $(+)$, kết quả cũng cho thấy có mối liên hệ thuận chiều với giá căn hộ. Giới hạn đường nội bộ và vỉa hè là phần diện tích bắt buộc, được quy định cụ thể trong quy hoạch $\mathrm{KDC}$ nhằm đảm bảo an toàn giao thông và tạo vẻ thẩm mỹ cho KDC nên không có sự chênh lệch lớn phần diện tích này ở những đường nội bộ khác nhau trong cùng một KDC hay với các KDC khác nhau. Vì vậy, cả hai biến này cũng không đủ mạnh để tác động đến giá căn hộ.

\section{Kết luận}

Kết quả phân tích có 10 nhân tố tác động đến giá mua căn hộ bao gồm tuổi căn hộ, diện tích căn hộ, số phòng, số tầng, vị trí tọa lạc, khoảng cách đến đường chính, khoảng cách đến trung tâm thành phố, kỳ vọng về giá, cấp sổ hồng và loại căn hộ. Trong đó, khoảng cách đến trung tâm thành phố có tác động mạnh nhất, càng cách xa trung tâm thì giá căn hộ càng giảm. Kế đến là yếu tố về loại căn hộ được xây thô sẽ có giá thấp hơn căn hộ được xây hoàn thiện. Diện tích căn hộ càng lớn giá giao dịch càng tăng nhưng tính trên đơn vị $\mathrm{m}^{2}$ thì giá sẽ càng giảm. Các yếu tố về tuổi căn hộ, số phòng, số tầng, vị trí tọa lạc, khoảng cách đến đường chính đều có tác động nghịch đến giá căn hộ. Hai nhân 
tố kỳ vọng về giá và cấp sổ hồng tỷ lệ thuận với giá căn hộ nhưng yếu tố kỳ vọng không ảnh hưởng lớn. Nhìn chung, với tốc độ phát triển kinh tế - xã hội của TPCT, thị trường nhà ở tại các KDC nói riêng và của toàn thành phố nói chung hứa hẹn sẽ phục hồi và mang đến cho người tiêu dùng một sự chọn lựa phù hợp với nhu cầu.

Để đảm bảo có nguồn cung nhà ở cho đối tượng thu nhập thấp đến năm 2020, lãnh đạo TPCT nên tiếp tục xem xét các chính sách hỗ trợ để khuyến khích các nhà đầu tư tham gia vào thị trường này. Tiếp tục đẩy mạnh công tác đơn giản hóa thủ tục hành chính để các dự án sớm triển khai đi vào hoạt động nhất là các dự án nhà ở xã hội. Các chủ đầu tư xây dựng nhà cần đa dạng các loại hình nhà ở trên thị trường, đa dạng các kích cỡ nhà, cấu trúc căn nhà, kiểu dáng nhà nhằm đáp ứng nhu cầu khác nhau của khách hàng; từ đó, hình thành nên những căn hộ với các mức giá khác nhau, phù hợp với đặc điểm của mỗi căn hộ. Ngoài ra, các nhà chủ đầu tư cần phát triển chính sách chiêu thị sản phẩm nhà thông qua nhiều hình thức như marketing qua truyền hình, internet... các kênh truyền thông, để thông tin một cách chi tiết các sản phẩm nhà ở đến với người có nhu cầu; hoặc thông qua hình thức mua nhà trả góp, đa dạng các hình thức quảng cáo và khuyến mãi để thu hút sự quan tâm của khách hàng ngày càng nhiều hơn./.

\section{Tài liệu tham khảo}

[1] Zvi Griliches (1971), Introduction: hedonic price indexes revisited, In Price indexes and quality change: Studies in new methods of measurement, ed., 3 - 15. Cambridge, MA: Harvard University Press.

[2] Chung-Ho Kim, Kyung-Hwan Kim (1999), "Expectation and Housing Price Dynamics Following Deregulation in Korea", International Real Estate Review.

[3] Nguyễn Quốc Nghi và cộng tác viên (2012), "Ứng dụng mô hình Hedonic xác định các nhân tố ảnh hưởng đến giá nhà cho thuê ở TPCT", Kỷ yếu khoa học, Trường Đai học Cần Thơ, tr. 186 - 194.

[4] Niên giám thống kê TPCT năm 2013.

[5] Lê Khương Ninh (2011), "Các yếu tố ảnh hưởng đến giá đất vùng ven đô thị ở ĐBSCL", Tap chí Phát triển kinh tế, (Số 254), tr. 11-17.

[6] Quyết định số 207/2006/QĐ-TTg, 2006, Quyết định của Thủ Tướng Chính phủ về việc phê duyệt Quy hoạch chung xây dựng TPCT đến năm 2025.

[7] Ronald G. Ridker, John A. Henning (1967), "The determinants of residental property values with special references to air pollution", The Review of Economics and Statistics.

[8] Malpezzi Stephen, Larry Ozanne, Thomas Thibodeau (2003), "Characteristic Prices of Housing in in Fifty-Nine Metropolitan Areas", The Urban Institute in Washington DC.

[9] Bảo Trân (2013), Cần Tho xây thi điểm nhà cho người thu nhập thấp, http://www.vietnamplus.vn/ can-tho-xay-thi-diem-nha-cho-nguoi-thu-nhap-thap/184957.vnp

[10] Raymond Y.C. Tse, Peter E.D. Love (2000), "Measuring residential property values in Hong Kong", Property Management, Vol. 18.

[11] Trần Thu Vân, Nguyễn Thị Giang (2011), "Ứng dụng mô hình Hedonic về các yếu tố ảnh hưởng giá bất động sản tại Thành phố Hồ Chí Minh", Tạp chí Phát triển kinh tế, (Số 254).

[12] Wen Hai-zhen (2005), "Hedonic price analysis of urban housing: An empirical research on Hangzhou, China", Journal of Zhejiang University Science, 6A8:907-914.

\section{FACTORS AFFECTING PURCHASE PRICE OF RESIDENTIAL APARTMENTS IN CAN THO CITY}

\section{Summary}

The study was conducted to determine factors affecting purchase price of residential apartments in Can Tho City. Hedonic model is used to determine these factors, based on a 183-household survey among 10 residential areas in Ninh Kieu and Cai Rang districts. The results show that there are 10 factors related: apartment age, area, room number, floor number, location, distance to the main road, distance to downtown, price expectation, ownership certificate and apartment type. Based on the obtained results, the authors propose recommendations for developing and managing residence market in Can Tho city.

Keywords: Hedonic model, factors, apartment purchase price, residential areas, Can Tho city.

Ngày nhận bài: 19/11/2015; Ngày nhận lại: 29/1/2016; Ngày duyệt đăng: 30/8/2016. 